\title{
Маломодовая волоконно-оптическая линия передачи с компенсацией дифференциальной модовой задержки и хроматической дисперсии на усилителях
}

\author{
В.А. Бурдин ${ }^{1}$, А.В. Бурдин ${ }^{1}$, К.А. Волков ${ }^{1}$, М.В. Дашков ${ }^{1}, \underline{\text { Е.Ю. Еремчук }}^{1}$ \\ ${ }^{I}$ Поволжский государственный университет телекоммуникаций и информатики \\ ${ }^{*}$ E-mail: eremchuk1989@yandex.ru
}

DOI:10.31868/RFL2018.139-140

C приближением пропускной способности современных транспортных сетей связи к так называемому «нелинейному пределу Шеннона» возрастает интерес к маломодовым оптическим волокнам, которые наряду с многосердцевинными волокнами рассматриваются в качестве альтернативы традиционным одномодовым оптическим волокнам на сетях связи. Разработаны конструкции маломодовых оптических волокон [1-3]. Известны примеры экспериментальной демонстрации возможностей технологии модового мультиплексирования с использованием таких волокон для линий дальней связи [4-6]. Технология модового мультиплексирования представляет существенный интерес для сетей связи следующего поколения, однако требует решения ряда проблем. В частности, проблемы влияния на качество передачи информации совместного действия факторов дифференциальной модовой задержки и связи мод, которые вместе с хроматической дисперсией, поляризационной модовой дисперсией и нелинейностью ограничивают пропускную способность и протяжность регенерационных участков волоконно-оптических линий передачи.

В данной работе методами математического моделирования на примере двумодовой волоконно-оптической линии передачи исследуются потенциальные возможности повышения качества передачи за счет компенсации дифференциальной модовой задержки и хроматической модовой дисперсии на линейных оптических усилителях. Для моделирования использовали модель и алгоритм [7], позволяющие учитывать связи мод, дифференциальную модовую задержку, хроматическую дисперсию и нелинейность оптических волокон. Рассматривалась линия связи протяженностью 6000 км с периодически установленными эрбиевыми оптическими усилителями при двух схемах компенсации дифференциальной модовой задержки: методом переключения мод и за счет включения линии задержки. Представлены результаты моделирования передачи сигналов с форматом модуляции DQPSK для канальной скорости 100 Гбит/с по маломодовому оптическиму волокну. Получены зависимости вероятности ошибок в оптическом канале на приеме в зависимости от способа и глубины компенсации дифференциальной модовой задержки, глубины компенсации хроматической дисперсии на линейных оптических усилителях.

\author{
Литература \\ [1] F. Ferreira, S. Jansen et al, IEEE Photonics Technology Letters 24(4), 240-242 (2012) \\ [2] A. Li, X. Chen et al,// J. Lightwave Technology 30(24), 3953-3964 (2012) \\ [3] L. Grüner-Nielsen, Y. Sun et al, J. Lightwave Technology 30(23), 3693-3698 (2012) \\ [4] F. Yaman, N. Bai et al, Opt. Express 18(20), 21342-21349 (2010) \\ [5] X. Chen, A. Li et al, Opt. Express 20(13), 14302-14307 (2012) \\ [6] M. Salsi, C. Koebele et al, Opt. Express 19(17), 16593-16600 (2012) \\ [7] В.А. Андреев, А.В. Бурдин и др., Вычислительные технологии 22(6), 4-11 (2017)
}

